\title{
Frequency-Magnitude Distribution of Earthquakes
}

\author{
Zuhair Hasan El-Isa \\ Additional information is available at the end of the chapter \\ http://dx.doi.org/10.5772/intechopen.77294
}

\begin{abstract}
Frequency magnitude distribution of all types of earthquakes has received considerable attention in the last few decades. Their linear logarithmic relationship remains the most accepted. The $a$ and $b$ constants of this equation, their values and variations have been studied in detail. It is largely agreed that for the seismicity of the whole Earth, its hemispheres, quadrants and large epicentral regions are $a=10.0$ and $b=1.0$. The $b$-variations have long been investigated and reported to occur in different forms and values. Long- and short-term b-variations occur in a continuous cyclic manner and may exceed $\pm(0.6-0.7)$ of its absolute value. These are observed to occur not only yearly or monthly but also daily. The $b$-value always attains maxima and minima before and after the occurrence of all large earthquakes. Many days before the occurrence of large earthquakes, $b$-values start increasing at variable gradients that are affected by foreshocks. It attains a maximum value shortly before each large earthquake and a minimum on its occurrence. Many factors have been proposed to explain the b-variations including prevailing stress, crustal heterogeneity, focal depth, pore pressure, geothermal gradient, tectonic setting, and other factors. Considering the b-variations of the whole Earth, its hemispheres and quadrants and considering that most proposed factors are directly or indirectly related to the stress, it is concluded that this remains the major factor. It is found that for large earthquakes with $\mathrm{Mw} \geq 7$, an increase of about 0.20 in the $b$-value implies a stress increase that will result in an earthquake with a magnitude one unit higher.
\end{abstract}

Keywords: earthquakes, b-value, spatiotemporal, seismicity, frequency-magnitude

\section{Introduction}

During the last few decades, different frequency-magnitude relationships have been proposed to explain the earthquake distribution in any region. These include the double power 
law and the exponential and Weibull distributions. The linear empirical relationship of Eq. (1) as originally suggested by [1-3] remains the most used among seismologists worldwide:

$$
\log N=a-b M
$$

where "N" is the total number of earthquakes with magnitudes $\geq \mathrm{M}$. The variable "a" represents the total seismicity rate and the level of seismic activity of a region, while the slope " $b$ " describes the relative size distribution of its earthquakes. Both parameters are of vital importance in seismicity, seismotectonics, and other related studies. The variable " $b$ " has received much more attention and was subjected to many statistical, analytical, and evaluation techniques within the last few decades. To illustrate the long-term global average of both a and $b$ values, [4] compiled the seismicity data for all earthquakes that occurred globally during the period January 1990-December 2012 with magnitudes $M \geq 4.5$ from the National Earthquake Information Centre (NEIC) of the US Geological Survey, the Incorporated Research Institutions for Seismology (IRIS), and the International Seismological Centre (ISC)

\begin{tabular}{|c|c|c|c|c|c|c|}
\hline & Region & & NEIC & IRIS & ISC & Average $b$-values \\
\hline \multirow{11}{*}{$\begin{array}{l}\text { Jan. 1, 2000-Dec. } \\
31,2010\end{array}$} & \multirow[t]{3}{*}{ Eastern Hemisphere } & \multirow{2}{*}{$\begin{array}{l}\text { No. of } \\
\text { earthqs }\end{array}$} & 45,775 & 48,318 & 81,121 & \multirow[t]{3}{*}{1.01} \\
\hline & & & \multirow[t]{2}{*}{1.03} & \multirow[t]{2}{*}{0.99} & \multirow[t]{2}{*}{1.01} & \\
\hline & & b-Values & & & & \\
\hline & \multirow{3}{*}{$\begin{array}{l}\text { Western } \\
\text { Hemisphere }\end{array}$} & \multirow{3}{*}{$\begin{array}{l}\text { No. of } \\
\text { earthqs } \\
\text { b-Values }\end{array}$} & 22,089 & 22,117 & 112,861 & \multirow[t]{3}{*}{1.02} \\
\hline & & & 1.08 & 0.96 & 1.01 & \\
\hline & & & & & & \\
\hline & \multirow[t]{3}{*}{ Whole Earth } & \multirow{3}{*}{$\begin{array}{l}\text { No. of } \\
\text { earthqs } \\
\text { b-Values }\end{array}$} & 67,864 & 70,435 & 193,983 & \multirow[t]{3}{*}{1.03} \\
\hline & & & \multirow[t]{2}{*}{1.07} & \multirow[t]{2}{*}{1.02} & \multirow[t]{2}{*}{1.01} & \\
\hline & & & & & & \\
\hline & Overall & & & & & $1.02 \pm 0.02$ \\
\hline & $b$-Average & & & & & \\
\hline \multirow{11}{*}{$\begin{array}{l}\text { Jan. 1, 1990-Dec. } \\
\text { 31, } 2012\end{array}$} & \multirow[t]{3}{*}{ Eastern Hemisphere } & \multirow{3}{*}{$\begin{array}{l}\text { No. of } \\
\text { earthqs } \\
\text { b-Values }\end{array}$} & 85,954 & 46,147 & 146,939 & \multirow[t]{3}{*}{1.02} \\
\hline & & & 1.04 & 1.06 & 0.96 & \\
\hline & & & & & & \\
\hline & Western & \multirow{3}{*}{$\begin{array}{l}\text { No. of } \\
\text { earthqs } \\
\text { b-Values }\end{array}$} & 39,809 & 102,337 & 204,099 & \multirow[t]{3}{*}{1.05} \\
\hline & Hemisphere & & 1.12 & 1.08 & 0.96 & \\
\hline & & & & & & \\
\hline & \multirow[t]{3}{*}{ Whole Earth } & \multirow{3}{*}{$\begin{array}{l}\text { No. of } \\
\text { earthqs } \\
\text { b-Values }\end{array}$} & 125,763 & 148,484 & 351,038 & \multirow[t]{3}{*}{1.03} \\
\hline & & & \multirow[t]{2}{*}{1.07} & \multirow[t]{2}{*}{1.07} & \multirow[t]{2}{*}{0.96} & \\
\hline & & & & & & \\
\hline & Overall & & & & & $1.03 \pm 0.03$ \\
\hline & $b$-Average & & & & & \\
\hline
\end{tabular}

Table 1. The a and b values as calculated by [4] for the whole Earth and its Eastern and Western Hemispheres utilizing compiled seismicity data from NEIC, IRIS, and ISC catalogs for the period Jan. 1, 1990-Dec. 31, 2012. 
catalogs and subjected the data to least-square regression analysis for the calculation of both a and $b$. Their results, Table 1, indicate that the a-value is mostly in the range 9.5-10.1 for the whole Earth and its hemispheres. With slight variations between the seismicity data of the three sources and the major regions of the Earth, the a-value averages at about 10.0. These values are in agreement with most previous published results, for example, see [5-13].

Both parameters show a relatively wide range of spatial and temporal variations, particularly the b-value, which displays continuous local, regional, and global fluctuations on various timescales of up to $0.5-0.8$ of its absolute value or more $[4,14]$. On a local scale, it shows a relatively wide range of variation (0.3 to 2.5$)$ or more, for example, see $[1,4,7,11,12,14-36]$ and references therein]. Such b-variations are known to accompany microearthquakes as reported in a few laboratory experiments [17], to induced earthquakes associated with mining, large water reservoirs, and other man-made activities [18, 38-40], to large tectonic earthquakes $[4,14,41-44,46]$. A few studies, however, contradict with this and claim that such temporal and spatial b-variations are apparent and interpreted them as artifact rather than natural, for example, see $[6,8,47,48]$. Some studies claim that temporal variations are of second order compared to the spatial variations and are generally more difficult to observe [7, 30, 33]. Details on the regional and global spatiotemporal b-variations, their characteristics, their classifications, and the main factors affecting them are presented and discussed in this chapter.

\section{Classification and causes of b-variations}

In their review, [4] reported the following classification as compiled from published literature on the b-variations:

1. An increase in the b-value before the occurrence of major earthquakes during variable periods of time that extend many years in some cases and an immediate drop soon after their occurrence. Case studies cover different parts of the world, for example, Venezuela [20], China [22], and New Zealand [24].

2. A decrease in the b-value before the earthquake for variable periods of time that may be many years in some cases and an increase thereafter $[5,7,17,18,29,31,33,35,39,43,44$, $49,50]$.

3. An increase in the b-value long before the main earthquake followed by a short-term drop shortly before its occurrence [27, 28, 51].

4. Continuous cyclic b-variations that occur over the years, months, and days both locally and regionally. The short-term variations are much larger and may exceed $0.7-0.8$ of its absolute value. A few weeks before major earthquakes, the b-value starts increasing gradually with variable gradients that are affected by relatively large foreshocks. Soon before the earthquake, the b obtains a maximum and drops down to a minimum on its occurrence $[4,14]$.

5. A limited number of studies claim that b-variations are apparent and interpreted to be artifact rather than natural and are thus considered insignificant, for example, see [6, 8, 47, 48]. 
Such studies are limited compared to the many studies that report and confirm the spatial and temporal b-variations.

The factors that affect all reported spatiotemporal b-variations have been compiled and discussed by $[4,14]$ who claim that such variations are caused by one or more of the following factors:

1. An increase in the applied stress or effective stress is believed by many researchers to result in a b-decrease and vice versa, e.g., [7, 30-33, 35, 41-44]. This is evidenced by some limited laboratory experiments $[15,17]$. Other studies however report that the b-value increases before the major earthquake, i.e., with stress and decreases thereafter [22, 24]. From their calculations to the b-variations of the whole Earth, its two hemispheres and four quadrants $[4,14]$ concluded that the stress remains the major factor that affects b-variations. The $b$ increases with stress and shows gradual increase to maxima soon before large earthquakes and minima on their occurrence.

2. Variations in crustal heterogeneity, either primary or secondary, the second being brought about by one or both of the following causes: (a) rock deformations due to their folding, faulting, fracturing, cracking, and micro-cracking and (b) liquid and other magmatic materials invading the subsurface rocks. Fluid and pore pressure increase is believed by some to increase the $b$-value, for example, see $[7,19,30]$. In general, the b-value is reported to increase with the crustal heterogeneity [52-54].

3. Latent heat as introduced to the rocks by intrusions is believed to increase the $b$-values. Limited laboratory experiments are claimed to support this idea $[25,55]$; see also $[30,33$, $35,43,44]$.

4. Tectonic characteristics and focal mechanisms have long been suggested to cause b-variations $[15,16,23]$. Normal faulting is believed to be associated with relatively high b-values, strike-slip with intermediate, while thrust faulting is claimed to have the lowest b-values $[1,41,56-58]$. Creeping segments of faults appear to display high b-values, while asperities are reported to be characterized by anomalously low b-values [7, 33]. Ref. [26] have reported low b-values in the upper boundary of the subducting plates and high in the lower plane; see also $[29,56]$. Contrary to this, other researchers suggest that there is little variation of $b$ between different tectonic regions, for example, see $[6,8]$.

5. Petrological, environmental, depth, and some geophysical characteristics of rocks are reported in many cases to display b-variations. From his laboratory measurements, [17] reported that frictional sliding and deformation of a ductile rock were found to have higher b-value than that observed in brittle rocks. Variations in the b-values with depth are reported in different localities, e.g., California, where it is reported to decrease with depth [7, 30, 53]. In some other regions, high and low b-values are related to low and high $\mathrm{P}$-wave velocities, respectively [26, 59]. On land, low Bouguer anomalies are reported to correlate with low b-values, while the opposite is suggested for offshore anomalies [25]. In one case, temporal b-variations are suggested to be caused by seismicity migration [21].

6. In each b-calculation for any region, the magnitude scale for all earthquakes should be the same. Using different scales in the one set of calculation or different calculations will 
result in different $b$-values. [31] deduced a b-value $=1.5$ for Mexican earthquakes utilizing the duration magnitude (Md) and a b-value $=0.85$ for the same set of earthquakes when magnitudes were converted to Ms.

7. It was reported by $[4,14]$ that the $b$-variations are also affected by the selected calculating technique and how it is applied. The most used methods in the b-calculations are the regression and the maximum likelihood [60-62]. Both methods are sensitive to small numbers of earthquakes in the time window, but a reasonable correlation is observed between the results of both methods, as long as the numbers of earthquakes in the analyzed windows are large [14]. The calculated $b$-values are also affected, albeit slightly, by the length of the time window. They also show some slight variations between the use of moving and expanding time windows utilizing the same technique, though corelatable results are mostly obtained $[4,14]$.

\section{Spatiotemporal b-variations}

A detailed review by [4] briefs details on these variations, their classification, and their causes and includes most related references. The seismicity of the whole Earth, its two hemispheres and four quadrants, and the epicentral regions of some selected recent earthquakes has been evaluated by $[4,14]$ to conclude that b-variations occur continuously not only yearly but monthly and daily and to show that the applied stress remains the main factor that affects these variations. These were classified as follows [4, 14]:

\subsection{Long-term b-variations}

Detailed b-calculations on the seismicity of the Earth and its Eastern and Western Hemispheres that occurred during the period 1990-2010 were made by [14] for different periods of 1, 2, 11, and 21 years; see Table 2. Results show that the overall average $b$-value for the whole Earth

\begin{tabular}{|c|c|c|c|c|c|c|}
\hline \multirow[t]{6}{*}{ Region } & Jan. 1,1990 , to & Jan. 1,2000 , to & Jan. 1-Dec. 31, & Jan. 1-Dec. 31, & Jan. 1, 2004- & Jan. 1-Dec. 31, \\
\hline & Dec. 31, 2010 & Dec. 31, 2010 & 2004 & 2005 & Dec. 31, 2005 & 2010 \\
\hline & No. of $b$-value & No. of $b$-value & No. of $b$-value & No. of $b$-value & No. of $b$-value & No. of $b$-value \\
\hline & Earthqs. & Earthqs. & Earthqs. & Earthqs. & Earthqs. & Earthqs. \\
\hline & and magn. & and magn. & and magn. & and magn. & and magn. & and magn. \\
\hline & range & range & range & range & range & range \\
\hline \multirow[t]{2}{*}{ Whole Earth } & $111,2971.109$ & $68,0431.056$ & 61870.939 & 78831.034 & $14,0700.972$ & 73651.064 \\
\hline & $4.5-9.1 \pm 0.001$ & $4.5-9.1 \pm 0.001$ & $4.5-9.1 \pm 0.058$ & $4.5-8.6 \pm 0.018$ & $4.5-9.1 \pm 0.021$ & $4.5-8.8 \pm 0.004$ \\
\hline \multirow{2}{*}{$\begin{array}{l}\text { Eastern } \\
\text { Hemisphere }\end{array}$} & $75,4511.084$ & $45,9891.029$ & 42150.886 & 60370.993 & $10,2520.923$ & 42280.961 \\
\hline & $4.5-9.1 \pm 0.002$ & $4.5-9.1 \pm 0.002$ & $4.5-9.1 \pm 0.056$ & $4.5-8.6 \pm 0.018$ & $4.5-9.1 \pm 0.027$ & $4.5-7.8 \pm 0.007$ \\
\hline \multirow{2}{*}{$\begin{array}{l}\text { Western } \\
\text { Hemisphere }\end{array}$} & $35,8461.105$ & $22,0541.074$ & 19721.115 & 18461.031 & 38181.107 & 31371.077 \\
\hline & $4.5-8.8 \pm 0.002$ & $4.5-8.8 \pm 0.002$ & $4.5-7.2 \pm 0.006$ & $4.5-7.8 \pm 0.009$ & $4.5-7.8 \pm 0.002$ & $4.5-8.8 \pm 0.005$ \\
\hline
\end{tabular}

Table 2. The $b$-values for the whole Earth and its Eastern and Western Hemispheres as calculated for different long periods of time utilizing the NEIC 1990-2010 seismicity data (M $\geq 4.5)$, slightly modified from [14]. 
and its two hemispheres is $1.06 \pm 0.02$ with limited variations of about $(0.09)$ between the three studied regions. The maximum differences in $b$-values $(\Delta b)$ for the different periods of time are 0.17, 0.198, and 0.084 for the whole Earth and its Eastern and Western Hemispheres, respectively. Such results confirm that the derived $b$-values show clear temporal and spatial variations but with rather limited values [4, 14].

\subsection{Short-term (monthly) b-variations}

Seismicity data of the Eastern Hemisphere as reported in the catalogs of the three NEIC, IRIS, and ISC sources during the years 2009-2011 were utilized by [14] to study short-term $b$-variations using fixed time windows 1 month long, Figure 1 and Table 3. Continuous cyclic $b$-variations are observed on the three curves of Figure 1. The monthly $b$-differences $(\Delta b)$ as obtained from the NEIC data are $0.38,0.33$, and 0.62 for the months of the 3 consecutive years in respective order. The difference between the lowest and highest $b$-values during the 3 years together is 0.83 . The $b$-results of the IRIS and ISC sets of data correlate with the first and show large systematic cyclic variations and differences that vary mostly in the range $0.40-0.70$; see Table 3. Further b-calculations were made by [14] on the NEIC seismicity data that occurred within Quadrant 1 during the 2 years 2004 and 2005 using time windows 1 month and 2 months. More calculations are made in this study for the same data using time windows 3 months long. Results are plotted in Figure 2 and Figure 3.

Continuous cyclic monthly $b$-variations have occurred through the months of the 2 years in the range 0.68-1.43. During January and February 2004, it increased from about 0.93 to 1.3-1.4. During the following 2 months of the same year, it decreased to about 0.97-0.98. During the period May-July, it increased to about 1.1 and to about 1.34 in August. A general decrease is observed to have occurred during the period September-December 2004 to about 0.675. Further $b$-variations are observed to have taken place during the year 2005 when the



Figure 1. Continuous monthly $b$-variations as calculated by [14] from the seismicity data of NEIC (blue), ISC (red), and IRIS (green) that occurred during the period 2009-2011 with $M \geq 4.5$. Bars represent the calculated standard errors. 


\begin{tabular}{|c|c|c|c|c|c|}
\hline & & 2009 & 2010 & 2011 & 2009-2011 \\
\hline \multirow[t]{3}{*}{ NEIC } & Earthq. no./month & $236-479$ & $228-698$ & $342-2220$ & 0.83 \\
\hline & $\Delta b /$ year & 0.38 & 0.33 & 0.62 & \\
\hline & $\Delta b / 3$ years & & & & \\
\hline \multirow[t]{3}{*}{ IRIS } & Earthq. no./month & $183-438$ & $232-767$ & $321-2253$ & 0.68 \\
\hline & $\Delta b /$ year & 0.49 & 0.68 & 0.46 & \\
\hline & $\Delta b / 3$ years & & & & \\
\hline \multirow[t]{3}{*}{ ISC } & Earthq. no./month & $437-840$ & $524-1145$ & $530-3058$ & 0.70 \\
\hline & $\Delta b /$ year & 0.55 & 0.28 & 0.40 & \\
\hline & $\Delta b / 3$ years & & & & \\
\hline
\end{tabular}

Table 3. Ranges of the monthly number of earthquakes and the calculated $b$-values as calculated by [14] for the Eastern Hemisphere of the Earth utilizing the seismicity data ( $\mathrm{M} \geq 4.5)$ of NEIC, IRIS, and ISC for the period 2009-2011.

maximum observed value (1.43) occurred in September. Some 22 earthquakes including all with magnitudes $\geq 7.0$ and some M6.0-M6.9 earthquakes are also marked on the graph according to their times of occurrence. Further $b$-calculations were made to $(22 \times 2)$ time windows that include the seismicity data of each of the selected 22 earthquakes on its own; 1 window ends a day before and the other on the day of its occurrence. The time lengths of all windows varied mostly in the range 25 days-35 days. Results are plotted in red in Figure 2 and Figure 3. These show that for all 22 earthquakes, each $b$-value achieved a maximum 1 day before and a minimum soon after its occurrence. Soon after that, the $b$-values continue to change either positively, e.g., the two largest Sumatra earthquakes, or negatively as seen on some cases of Figure 2, e.g., the M7.4 earthquake of September 6, 2004, and the M7.2 earthquake of July 2005. The 2-month window results, Figure 3A, display continuous $b$-variations with time in the range 0.71-1.37. A general $b$-decrease is observed during the period April-December 2004, and a general increase is observed thereafter up to the end of June 2005 before starting to decrease again. Such results show good correlation with the 1-month results as far as their time and amplitude are concerned [14]. Similar cyclic variations are also observed on the 3-month data of Figure 3B.

The monthly b-results clearly indicate that b-variations are cyclic and continuous and may be as large as $0.7-0.8$ of the absolute $b$-value of the Earth or slightly more. These are much higher than long-period $b$-variations as deduced for a full year, 2 years, or larger periods.

\subsection{Short-time (daily) $b$-variations}

Monthly b-calculations were made by [14] to the seismicity of the whole Earth, its two hemispheres, and its four quadrants for periods of about 1 month that include the dates of occurrence of the largest three earthquakes of the year 2010, namely, the Mw 8.8 Chile earthquake of February 27, Quadrant 3; a Mw 7.8 Sumatra earthquake that occurred on April 6, Quadrant 1; and a Mw 7.8 earthquake that occurred on October 25 in Quadrant 2. Results are included in Table 4 . These show that the $b$-value of each quadrant and the whole Earth was maxima 


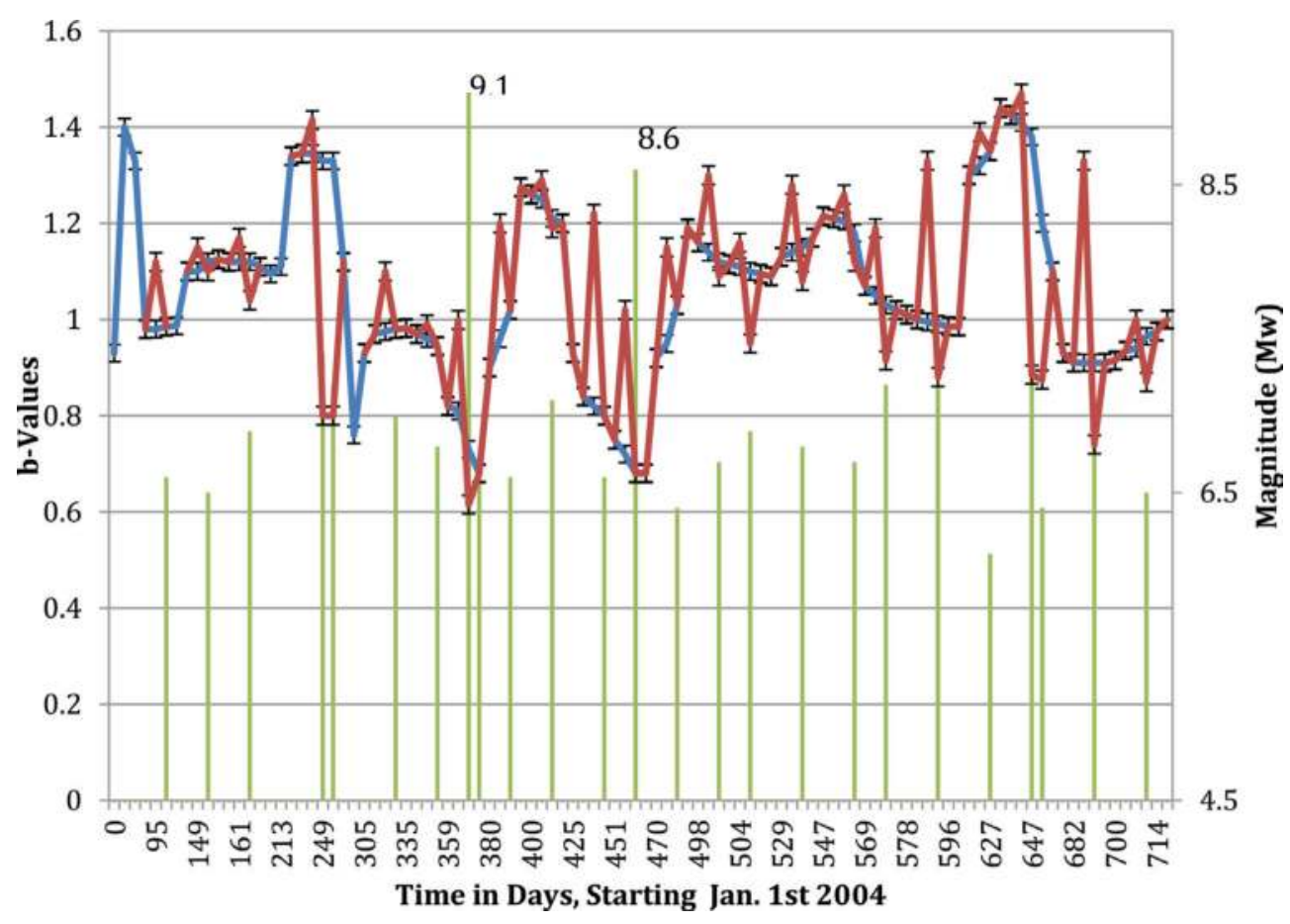

Figure 2. Continuous monthly b-variations as calculated by [14] for Quadrant 1 of the Earth from its 2004-2005 seismicity (blue line) and the calculated b-values 1 day before and soon after the occurrence of 22 selected earthquakes (in red) including the largest two Sumatra earthquakes of Dec. 2004 and March 2005.

soon before the occurrence of its earthquake and got reduced to minima soon after that. The total reduction in the $b$-value of Quadrant 3 where the Chile earthquake occurred is 0.350 . The same phenomenon is observed for the whole Earth whose $b$-value decreased in the Chile earthquake case by 0.294 . In the Sumatra case, the $b$-value of Quadrant 1 and the whole Earth dropped down by 0.122 and 0.187 , respectively. In the third case, the b-value of Quadrant 2 and the Earth got reduced by 0.546 and 0.351 [14].

Further $b$-calculations were made to the seismicity data of Quadrant 3 which occurred a few weeks before the Chile earthquake. Fixed time windows 15 and 20 days long that were moved 1 day at a time and daily expanding time windows were used in the b-calculations. Results are plotted in Figure 4 which also shows the times and magnitudes of the earthquakes that occurred within the same quadrant during the same period with magnitudes $\mathrm{Mw} \geq 5.6$. All earthquakes that occurred before the Chili earthquake are not located in its epicentral area. The expanding window results (red color) show that the $b$-value has varied gradually in the range 1.366-0.739 during the 54 days of calculation. The b-gradient has also varied during this period. It decreased with the occurrence of relatively large earthquakes and increased soon afterward; see [14] for details. On the occurrence of this major earthquake and its immediate aftershocks, the calculated $b$-value of Quadrant 3 got reduced to a minimum value, 0.739 . 
(A)

Days starting January 1, 2004

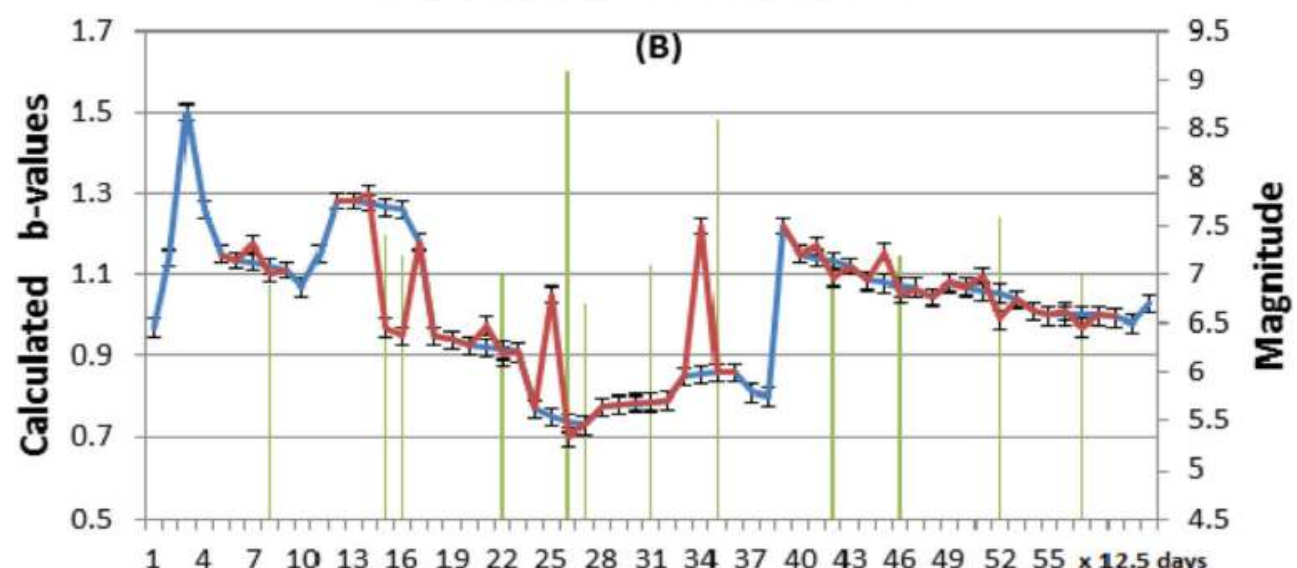

Days starting January, 1st, 2004

Figure 3. The $b$-values as calculated from the 2004 and 2005 seismicity data of Quadrant 1 utilizing time windows of fixed periods: (A) 2 months [14] and (B) 3 months as shown by the blue lines. The red lines show the calculated $b$-values for some selected large earthquakes utilizing time windows that end 1 day before and after their occurrence.

Continuous b-increase with variable gradients is observed to occur during the following 2 weeks, being largest within the first 1-2 days. All marked earthquakes of this period were epicentered close to the major Chile earthquake and are observed to have resulted in lowering the $b$-gradient; see Figure 4. Large b-variations are also noted on the moving-window results (blue and black curves). Differences between the highest and lowest $b$-values are 0.55 and 0.626 for the 15- and 20-day windows, respectively. Both curves show a gradual $b$-increase during the first $12-17$ days. The large b-value increase on both curves on January 20 and 25 is simply caused by the removal of the 6.8 earthquake of January 5 from the windows. Maximum b-values are observed on both windows and that of the expanding during the period February 8-9. On the occurrence of the major 8.8 Chile earthquake and its aftershocks, the $b$-value of both windows dropped down to about 0.7 . Continuous b-increase is observed on both windows during the following 14 days; for more details, see [14]. 


\begin{tabular}{|c|c|c|c|c|c|c|}
\hline \multirow[t]{5}{*}{ Region } & Feb. 1-26 & Feb. 1-27 & Mar. 1-Apr. 5 & Mar. 1-Apr. 6 & Oct. 1-24 & Oct. $1-25$ \\
\hline & No. of b-value & No. of $b$-value & No. of $b$-value & No. of $b$-value & No. of $b$-value & No. of $b$-value \\
\hline & Earthqs. & Earthqs. & Earthqs. & Earthqs. & Earthqs. & Earthqs. \\
\hline & and magn. & and magn. & and magn. & and magn. & and magn. & and magn. \\
\hline & range & range & range & range & range & range \\
\hline \multirow[t]{2}{*}{ Whole Earth } & 3831.063 & 6400.769 & 10321.133 & 10461.011 & 3741.286 & 4050.935 \\
\hline & $4.5-7.2 \pm 0.006$ & $4.5-8.8 \pm 0.059$ & $4.5-7.2 \pm 0.022$ & $4.5-7.2 \pm 0.008$ & $4.5-6.5 \pm 0.005$ & $4.5-7.8 \pm 0.041$ \\
\hline \multirow{2}{*}{$\begin{array}{l}\text { Eastern } \\
\text { Hemisphere }\end{array}$} & 2120.928 & 2220.939 & 3130.907 & 3210.872 & 2201.365 & 2470.85 \\
\hline & $4.5-7 \pm 0.01$ & $4.5-8.8 \pm 0.009$ & $4.5-6.5 \pm 0.008$ & $4.5-7.8 \pm 0.02$ & $4.5-6.2 \pm 0.039$ & $4.5-7.8 \pm 0.078$ \\
\hline \multirow{2}{*}{$\begin{array}{l}\text { Western } \\
\text { Hemisphere }\end{array}$} & 1711.146 & 4180.73 & 7191.108 & 7251.109 & 1541.112 & 1581.117 \\
\hline & $4.5-6.1 \pm 0.016$ & $4.5-7.2 \pm 0.09$ & $4.5-7.2 \pm 0.008$ & $4.5-7.2 \pm 0.008$ & $4.5-6.5 \pm 0.1$ & $4.5-6.5 \pm 0.01$ \\
\hline Quadrant 1 & 1100.80 & 1200.821 & 2000.997 & 2050.810 & 1261.226 & 1261.226 \\
\hline Lat $0^{\circ}-90^{\circ} \mathrm{N}$ & $4.5-7.0 \pm 0.01$ & $4.5-7.0 \pm 0.016$ & $4.5-6.7 \pm 0.002$ & $4.5-7.8 \pm 0.003$ & $4.5-6.3 \pm 0.007$ & $4.5-6.3 \pm 0.007$ \\
\hline \multicolumn{7}{|c|}{ Long $0^{\circ}-180^{\circ} \mathrm{E}$} \\
\hline Quadrant 2 & 1021.043 & 1021.043 & 1130.806 & 1160.811 & 941.274 & 1180.728 \\
\hline Lat $0^{\circ}-90^{\circ} \mathrm{S}$ & $4.5-6.2 \pm 0.022$ & $4.5-6.2 \pm 0.022$ & $4.5-6.8 \pm 0.002$ & $4.5-6.8 \pm 0.003$ & $4.5-5.9 \pm 0.005$ & $4.5-7.8 \pm 0.008$ \\
\hline \multicolumn{7}{|c|}{ Long $0^{\circ}-180^{\circ} \mathrm{E}$} \\
\hline Quadrant 3 & 1271.067 & 3730.717 & 6401.101 & 6441.102 & 921.01 & 1291.019 \\
\hline Lat $0^{\circ}-90^{\circ} \mathrm{S}$ & $4.5-6.1 \pm 0.008$ & $4.5-8.8 \pm 0.098$ & $4.5-6.9 \pm 0.004$ & $4.5-6.9 \pm 0.006$ & $4.5-5.9 \pm 0.007$ & $4.5-5.9 \pm 0.009$ \\
\hline \multicolumn{7}{|l|}{$\begin{array}{l}\text { Long } \\
0^{\circ}-180^{\circ} \mathrm{W}\end{array}$} \\
\hline Quadrant 4 & 441.041 & 450.954 & 790.766 & 810.769 & 620.868 & 640.873 \\
\hline Lat $0^{\circ}-90^{\circ} \mathrm{N}$ & $4.5-5.9 \pm 0.002$ & $4.5-5.9 \pm 0.005$ & $4.5-7.2 \pm 0.004$ & $4.5-7.2 \pm 0.004$ & $4.5-6.7 \pm 0.01$ & $4.5-6.7 \pm 0.015$ \\
\hline \multicolumn{7}{|l|}{$\begin{array}{l}\text { Long } \\
0^{\circ}-180^{\circ} \mathrm{W}\end{array}$} \\
\hline
\end{tabular}

Table 4. The calculated $\boldsymbol{b}$-values of the whole Earth and its Eastern and Western Hemispheres and four quadrants 1 day before and after the occurrence of the largest three earthquakes of 2010 [14].

Utilizing the expanding time window technique, further b-calculations were made by [14] to the seismicity of Quadrant 1 where the two largest Sumatra earthquakes of December 26, 2004 (M9.1), and March 28, 2005 (M8.6), occurred. In the case of the M9.1 earthquake, $29 b$-values were calculated utilizing the seismicity data of 29 time windows that have the same starting point, December 1; see Figure 5A. A general b-increase is very clear with gradient variations that correlate with the marked earthquakes. On December 6, the b-value got reduced to 0.612 due to the occurrence of a M6.8 earthquake. Soon after that it started increasing at a gradient of about 0.05 /day up to December 11. At this time a few earthquakes occurred with $M \leq 5.5$ which resulted in lowering the gradient to about 0.02/day. On December 18, the b-value and its gradient were reduced to 0.925 and about 0.011 /day, respectively, as caused by the occurrence of a M 6.2 earthquake. On December 25, a maximum b-value of 0.999 is calculated. It 


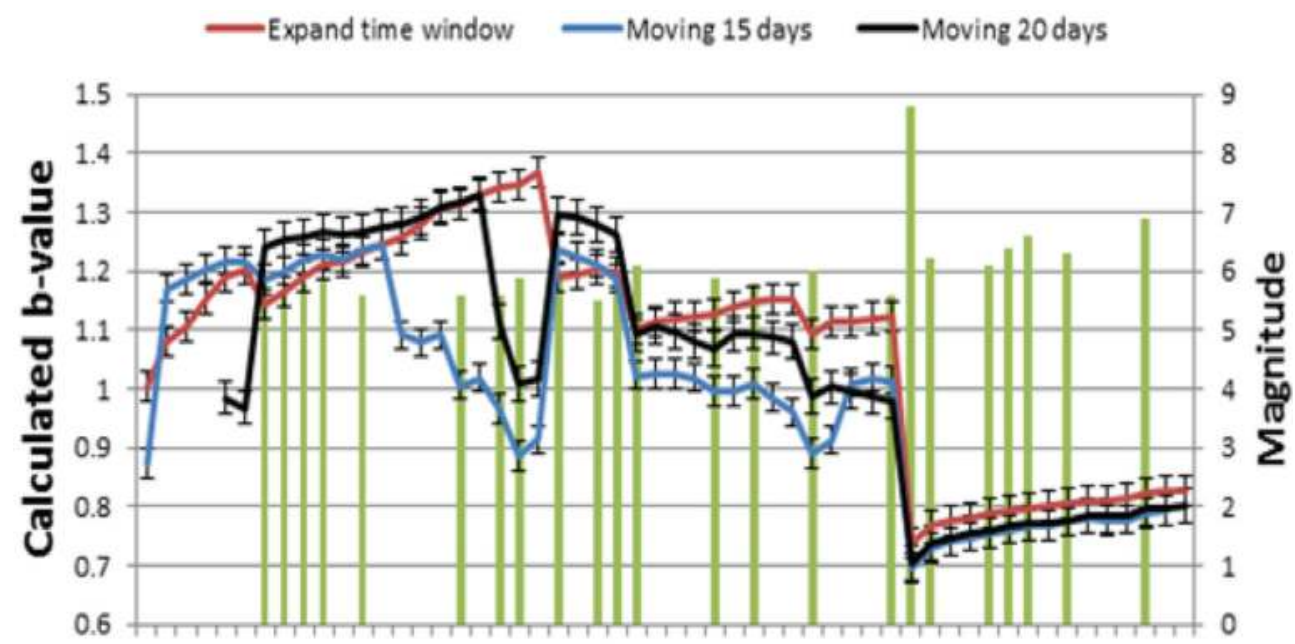

192123252729313335373941434547495153555759616365676971

Days starting January, 19, 2010

Figure 4. Variation of the $b$-values in Quadrant 3 of the Earth during a period of 39 days before and 14 days after the Chile, 2010, earthquake $(\mathrm{Mw}=8.8)$ as calculated by [14].

dropped down to 0.612 after the occurrence of the major Sumatra earthquake and its aftershocks; see Figure 5A. Continuous b-increase is observed afterward with variable gradients. These results clearly demonstrate how the $b$-value of Quadrant 1 of the Earth increased gradually for some time before the Sumatra earthquake of December 26, 2004 (M9.1), to a maximum soon before its occurrence and dropped down to a minimum after that. The occurrence of smaller earthquakes has reduced the $b$-value and its rate of increase [14].

Similar b-evaluations were made by [14] from the seismicity data of Quadrant 1 to study the $b$-variations before and after the occurrence of the second largest Sumatra earthquake of March 28 , 2005. Figure $6 \mathrm{~B}$ displays the final results which show a general b-increase up to March 27 with variable gradients, $0.039 /$ day for the first week, $0.017 /$ day during the second week, $0.047 /$ day during the third week, and a smaller gradient of only $0.002 /$ day during the last 2 days before the main earthquake. The largest b-value (1.142) is calculated for March 27. On the occurrence of the main shock, it was reduced to 0.628 , i.e., $\Delta b=0.514$. During the following 6 days, the $b$-values started increasing again at a rate of $0.014 /$ day. Similar to the previous earthquake, the $b$-values and their gradients are reduced with foreshock and aftershock occurrences; see Figure 6B [14].

Utilizing the moving and the expanding time windows further, daily b-calculations were made by [14] to the seismicity data of the epicentral area of the Sumatra 2005 earthquake and Quadrant 1 for a period of about 45 days before and 10 days after its occurrence; see Figure 6. A good correlation is observed between the two expanding curves (red and black). This correlation leads [14] to conclude that the $b$-values of Quadrant 1 and their variations were mainly controlled by the same factors as those in the Sumatra epicentral area during this period of time. Upon the 
(A)

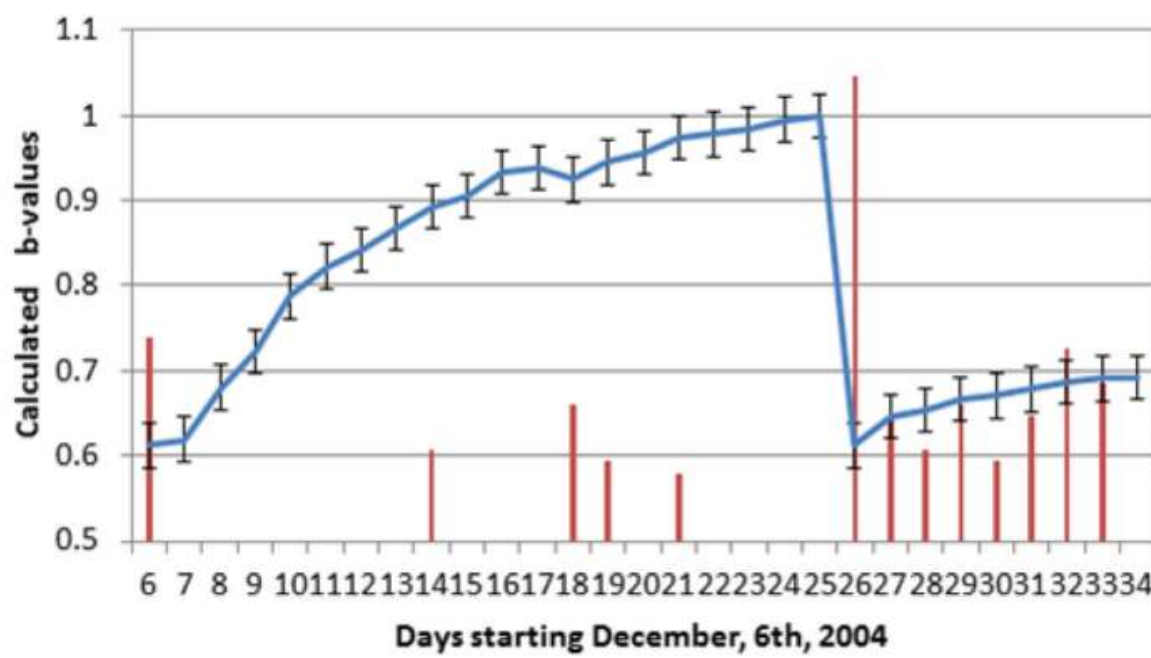

(B)

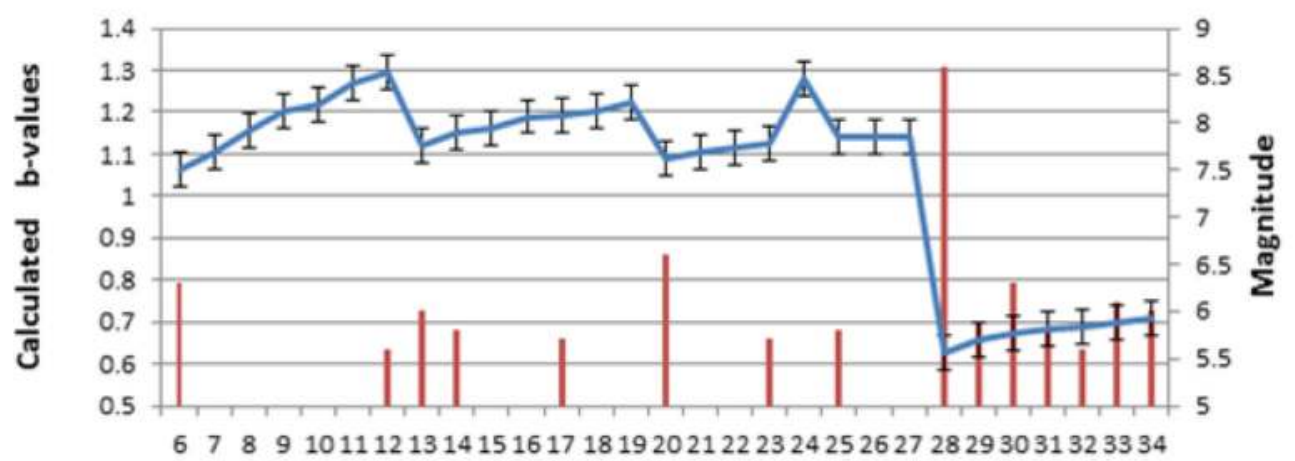

Days starting March, 6th, 2005

Figure 5. Calculated $b$-values for Quadrant 1 during a period of 29 days before and after the occurrence of (A) the largest Sumatra earthquake of December 26, 2004, and (B) the second largest Sumatra earthquake of March 28, 2005. All earthquakes of the study period that occurred in Quadrant 1 with $M \geq 5.6$ are marked with their dates and magnitudes, slightly modified from [14].

occurrence of the major earthquake (M8.6), the $b$-value of the epicentral area got reduced by 0.546 and that of Quadrant 1 by 0.331 . The M6.8 foreshock that occurred on February 26 resulted in a reduction of the $b$-value of the epicentral area by 0.260 and that of quadrant 1 by 0.119 . Note that during the last 2 days before the 8.6 major earthquake, the rate of $b$-increase of Quadrant 1 got reduced to less than $0.001 /$ day, while that of the epicentral area reduced to about $0.0013 /$ day [14].

The blue and green curves of Figure 6 represent the $b$-variations as calculated for both epicentral region and Quadrant 1, utilizing a 15-day window that moves daily starting 


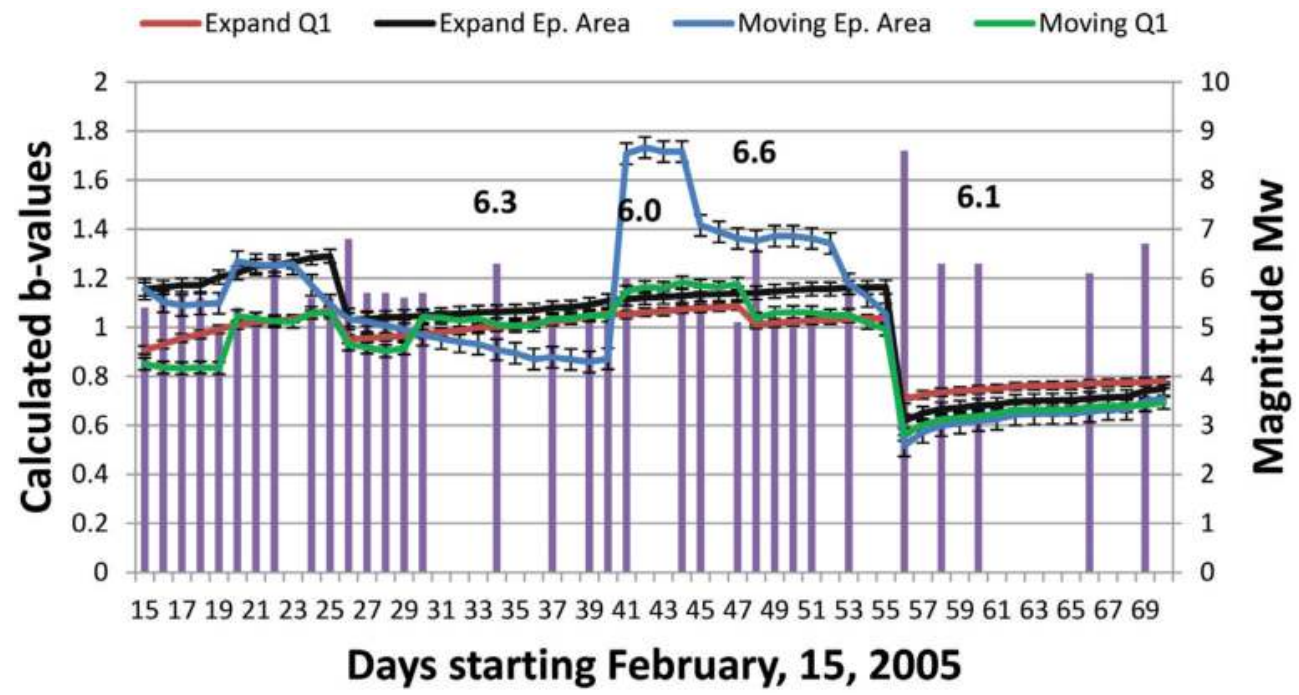

Figure 6. The $b$-variations as calculated by [14] for Quadrant 1 (red) and the epicentral area (black) of the Sumatra 2005 $\mathrm{Mw}=8.6$ utilizing daily expanding time windows. The first window expands between Feb. 8 and Feb. 15, while the last expands between Feb. 8 and April 11, 2005. The green and blue curves represent the calculated $b$-values for both regions utilizing a 15-day window that moves 1 day at a time. All epicentral earthquakes $M \geq 5$ are marked. Only four earthquakes $(\mathrm{Mw} \geq 6)$ occurred outside Sumatra epicentral region but within Quadrant 1 are marked with their magnitudes.

February 15, 2005. Both curves show a reasonable correlation and large $b$-variations. The epicentral values (blue) vary from a maximum of 1.732 on March 13 to a minimum of 0.517 on March 28 soon after the occurrence of the M8.6 earthquake. Between March 13 and 27 , the $b$-value appears to reduce almost continuously to 1.0541 day before the major earthquake. On March 13, its value jumped from 0.871 the day before, simply because on that day the M6.8 foreshock of February 26 was removed from the moving window. The continuous decrease beyond March 13 appears to correlate with the marked foreshocks, where the M6.6 foreshock of March 20 shows the largest effect. The following 3 days display a $b$-increase. A sharp decrease is observed soon after, which might be caused by the M5.8 earthquake of March 25 and other smaller magnitude events. The quadrant 1 curve (green) shows the same behavior with the removal of the 6.8 event and the addition of the M6.6, M5.8, and other foreshocks. The $b$-value got reduced to 0.991 on March 27 and to 0.563 on the occurrence of the M8.6 earthquake. Soon after that day, both curves show gradual increase, good correlation, and some deviations that correlate with the occurrence of aftershocks.

\section{Discussion}

It has long been documented that the a and $\mathrm{b}$ constants of the logarithmic frequency-magnitude distribution of earthquakes are of considerable importance in seismological, seismotectonic, and other related studies. Their regional and global values are 10.0 and 1.0, respectively, but 
both have long been reported to display considerable spatiotemporal variations [4-14]. The $b$-value is a quantitative measure of the earthquake size distribution within a certain period of time in any region. It has received much more attention, and numerous studies have investigated its value and variations. An increase in the number of small magnitude earthquakes increases its value, while it decreases with the occurrence of only one large earthquake or more. As the occurrence of earthquakes is unpredictable in both time and space, the $b$-value should therefore vary accordingly. It has long been known that the b-variations occur on both local and regional scales and are associated with all types of earthquake activities ranging from micro-tremors to very large tectonic earthquakes. Spatial variations vary from local tectonic areas to large tectonic regions, to a full quadrant of the Earth, to its hemispheres to the whole volume of the Earth $[4,14,37,45]$. Temporal variations of variable periods are reported to vary from many years to a few years to 1 year to a few months to 1 month and less $[1,4,12$, $14,34-36,38,47,48,57]$.

The most used techniques in the calculation of b-values are the linear regression and the maximum likelihood methods [33, 60, 61, 63-65]. Both methods give corelatable results for the same set of seismicity data but with differences of about $0.1-0.3$ of its absolute value or more $[4,14]$. The least-square regression method is disproportionately influenced by the largest earthquake magnitudes, while the maximum likelihood method weighs each earthquake equally $[65,66]$. The manner in which a method is applied, such as the magnitude range considered, the number of earthquakes per bin, the use of cumulative magnitude statistic, etc. can affect the calculated $b$-values. Other differences are also reported using the same technique depending on how it is used, i.e., using moving time windows of constant or variable lengths or expanding time windows, their lengths, etc.

The fact that the calculated long-period b-variations are much smaller than those of the short period is simply caused by the fact that these variations are of higher frequency and occur continuously through days and months [4, 14]. Most published b-calculations used equal numbers of earthquakes in moving time windows, i.e., unequal times. This results in combining seismicity data over long times, longer than times of variation, and thus, at least some of the temporal b-variations are not captured $[4,14]$. The time length of used windows and the total number of earthquakes used in the calculations are delicate factors that must be carefully considered in b-calculations. The use of moving fixed or expanding time windows influences both the number of earthquakes and their size distribution. These b-calculations clearly indicate that an expanding time window that starts at a fixed time appears to be a more effective technique to study the $b$-value and its variations, as all concerned earthquakes and their time distribution are retained within the studied time. In the moving-window technique, adding and removing large foreshocks and aftershocks result in relatively high $b$-variations. It is certain that both fixed and expanding window techniques confirm the b-variations, though their results vary slightly. Therefore combining the results of both techniques is quite useful [4, 14].

The b-calculations made by [4, 14] on the long-time and short-time sets of seismicity data clearly indicate that the $b$-value varies continuously with time in a cyclic manner. 
Long-time variations (1 year to many years long) are of relatively low amplitudes, while the short-time sets of data ( 1 or 2 months or shorter) show that the $b$-variations of the Earth as a whole, its hemispheres, and its quadrants, as well as the epicentral regions of large earthquakes attain continuous cyclic $b$-variations with amplitudes as high as 0.6-0.7 of its absolute value $[4,14]$. These variations occur not only yearly or monthly but also daily. Many days before the occurrence of large earthquakes, $b$-values start increasing with variable gradients that are affected by foreshocks. In some cases the gradient is reduced to zero or to a negative value a few days before occurrence of the main earthquake. In general, calculated $b$-values attain maxima 1 day before large earthquakes and minima soon after their occurrence followed by gradual increase thereafter with variable gradients caused by the aftershocks $[4,14]$.

For large earthquakes, the calculated $b$-variations of [14] show reasonable correlation for those of epicentral regions, the quadrant of the Earth, and the hemisphere they are located in as well as the whole Earth. This led him to conclude that these variations are of local and regional character, i.e., the geodynamic processes that cause the occurrence of such large earthquakes appear to act not only within the epicentral region but have a larger effect within the whole quadrant or more.

Spatiotemporal b-variations are influenced by a number of factors including stress, tectonic environment, crustal heterogeneity, depth, fluid and pore pressure, latent heat and geothermal conditions, and some geophysical and geotectonic characteristics [4, 14]. The $b$-variations of the Earth, its two hemispheres, and its four quadrants clearly indicate that the stress remains the major factor that affects these variations. In this case, the abovementioned regional factors are excluded, and the effects of much of the others are eliminated. It is concluded therefore that stress remains the most important factor that affects the $b$ and its variations as, firstly, it causes deformation of rocks including brittle failure, i.e., earthquakes, and, secondly, all other factors are directly related to and influenced by the stress.

\section{Conclusions}

The following conclusions are made:

1. The logarithmic linear relationship of the frequency magnitude distribution of earthquakes has received much attention during the last decades. The a and $b$ constants are critical parameters that have long been investigated and utilized in seismological, seismotectonic, and seismic hazard studies. Their regional, global, and long-term values are $\mathrm{a}=10.0$ and $\mathrm{b}=1.0$.

2. Spatiotemporal variations in the values of these constants, particularly the $b$, are manifested in numerous studies. The b-variations are expressed in different ways and have long been known to precede and follow the occurrence of large earthquakes. An increase in $b$ value for a number of years before an earthquake, followed by a decrease after its 
occurrence, or an increase long before the earthquake, followed by a small drop before the earthquake and a major decrease after its occurrence, has long been reported. Yearly, monthly, and daily b-variations are presented from other studies.

3. The $b$-variations are not only influenced by the different calculation techniques but also the way of using the same technique. Both linear regression and maximum likelihood methods give corelatable but variable results but with differences mostly in the range 0.1-0.3. It is found that an expanding time window technique from a fixed starting point is more effective in the study of $b$-variations. Combining the results of both techniques is certainly useful.

4. The calculated long-term and short-term b-variations of this study clearly indicate that $b$-variations occur in a continuous cyclic manner. The latter are of much higher value that may exceed $\pm(0.6-0.7)$ of its absolute value. These variations are observed to occur not only yearly or monthly but also daily, particularly before and after the occurrence of large earthquakes. The $b$-value always attains maxima and minima before and after the occurrence of all large earthquakes irrespective of the used method of calculation and how it is applied.

5. Spatiotemporal b-variations are influenced by a number of factors including stress, tectonic environment, crustal heterogeneity, depth, fluid and pore pressure, latent heat and geothermal conditions, and some geophysical and geotectonic characteristics. The $b$-variations of the Earth, its two hemispheres, and its four quadrants were interpreted by $[4,14]$ to conclude that the stresst remains the major factor that affects the $b$ and its variations. All other factors remain of secondary effect as all are directly or indirectly related to and influenced by the stress.

6. For large earthquakes, $b$-variations appear to be of both local and regional characters. This may indicate that in the case of large earthquakes, the geodynamic processes acting within an epicentral region appear to influence its concerned quadrant, hemisphere, and the whole Earth. This indicates that the geotectonic factors that cause large earthquakes are of regional and possibly global character.

7. For earthquakes with magnitudes $\mathrm{Mw} \geq 7.0$, it is found that an increase of about 0.20 in the $b$-value implies a stress increase that will result in an earthquake with a magnitude one unit higher, i.e., increasing the seismic energy some 28-30 times [14].

\title{
Author details
}

\author{
Zuhair Hasan El-Isa
}

Address all correspondence to: elisaz@go.com.jo

Department of Geology, University of Jordan, Amman, Jordan 


\section{References}

[1] Ishibe T, Tsuruoka H, Shimazaki K. The dependency of the b-value on the focal mechanism and on the hypocentral depth. Paper Presented at the Meeting of the Japan Geoscience Union Meeting, Chiba, Japan; 2008

[2] Gutenberg B, Richter C. Frequency of earthquakes in California. Bulletin of the Seismological Society of America. 1944;34(4):185

[3] Gutenberg B, Richter C. Seismicity of the Earth and Associated Phenomena. Vol. 2. Princeton University Press; 1954

[4] El-Isa ZH, Eaton DW. Spatiotemporal variations in the $b$-value of earthquake magnitude-frequency distributions: Classification and causes. Tectonophysics. 2014;615:1-11

[5] Imoto M. Changes in the magnitude-frequency b-value prior to large ( $\mathrm{M}$ 6.0) earthquakes in Japan. Tectonophysics. 1991;193(4):311-325

[6] Frohlich C, Davis S. Teleseismic b values; or, much ado about 1.0. Journal of Geophysical Research. 1993;98(B1):631-644

[7] Wiemer S, McNutt S, Wyss M. Temporal and three-dimensional spatial analyses of the frequency-magnitude distribution near Long Valley caldera, California. Geophysical Journal International. 1998;134(2):409-421

[8] Kagan Y. Universality of the seismic moment-frequency relation. Pure and Applied Geophysics. 1999;155(2-4):537-573

[9] Jaume S, Sykes L. Evolving towards a critical point: A review of accelerating seismic moment/energy release prior to large and great earthquakes. Pure and Applied Geophysics. 1999;155(2):279-306

[10] Stein S, Wysession M. An Introduction to Seismology, Earthquakes, and Earth Structure. Oxford: Blackwell Publishing; 2003

[11] Mishra O, Kayal J, Chakrabortty G, Singh O, Ghosh D. Aftershock investigation in the Andaman-Nicobar Islands of India and its seismotectonic implications. Bulletin of the Seismological Society of America. 2007;97(1A):S71

[12] Ghosh A, Newman A, Thomas A, Farmer G. Interface looking along the subduction megathrust from b-value mapping near Nicoya peninsula, Costa Rica. Geophysical Research Letters. 2008;35:L01301. DOI: 10.1029/2007

[13] Wech A, Kenneth W, Creager C, Houston H, Vidale J. An earthquake-like magnitudefrequency distribution of slow slip in northern Cascadia. Geophysical Research Letters. 2010;37:L22310

[14] El-Isa ZH. Continuous cyclic variations in the b-value of the earthquake frequencymagnitude-distribution. Earthquake Science. 2013:26(5):301-320 
[15] Mogi K. Study of elastic shocks caused by the fracture of heterogeneous materials and its relations to earthquake phenomena. Bulletin of the Earthquake Research Institute. 1962;40(1):125-173

[16] Mogi K. Earthquakes and fractures. Tectonophysics. 1967;5(1):35-55

[17] Scholz C. Microfracturing and the inelastic deformation of rock in compression. Journal of Geophysical Research. 1968;73(4):1417-1432

[18] Gibowicz S, Lasocki S. Seismicity induced by mining: Ten years later. Advances in Geophysics. 2001;44:39-181

[19] Wyss M. Towards a physical understanding of the earthquake frequency distribution. Geophysical Journal of the Royal Astronomical Society. 1973;31(4):341-359

[20] Fiedler G. Local b-values related to seismicity. Tectonophysics. 1974;23(3):277-282

[21] Udias A. Time and magnitude relations for three microaftershock series near Hollister, California. Bulletin of the Seismological Society of America. 1977;67(1):173

[22] Robinson R. Variation of energy release, rate of occurrence and b-value of earthquakes in the main seismic region, New Zealand. Physics of the Earth and Planetary Interiors. 1979;18(3):209-220

[23] Båth M. Earthquake recurrence of a particular type. Pure and Applied Geophysics. 1981;119(5):1063-1076

[24] Smith W. Evidence for precursory changes in the frequency-magnitude B-value. Geophysical Journal of the Royal Astronomical Society. 1986;86(3):815-838

[25] Wang J. b Values of shallow earthquakes in Taiwan. Bulletin of the Seismological Society of America. 1988;78(3):1243

[26] Ogata Y, Imoto M, Katsura K. 3-D spatial variation of b-values of magnitude-frequency distribution beneath the Kanto District, Japan. Geophysical Journal International. 1991;104(1):135-146

[27] Sahu O, Saikia M. The b value before the 6th August, 1988 India-Myanmar border region earthquake-A case study. Tectonophysics. 1994;234(4):349-354

[28] Gupta S, Singh V, Kumar A. Attenuation of coda waves in the Garhwal Himalaya, India. Physics of the Earth and Planetary Interiors. 1995;87(3-4):247-253

[29] Wiemer S, Benoit J. Mapping the B-value anomaly at $100 \mathrm{~km}$ depth in the Alaska and New Zealand Subduction zones. Geophysical Research Letters. 1996;23(13):1557-1560

[30] Wiemer S, Wyss M. Mapping the frequency-magnitude distribution in asperities: An improved technique to calculate recurrence times? Journal of Geophysical Research. 1997;102(B7):15115-15115

[31] Zuniga F, Wyss M. Most-and least-likely locations of large to great earthquakes along the Pacific coast of Mexico estimated from local recurrence times based on b-values. Bulletin of the Seismological Society of America. 2001;91(6):1717 
[32] Gerstenberger M, Wiemer S, Giardini D. A systematic test of the hypothesis that the b value varies with depth in California. Geophysical Research Letters. 2001;28(1):57-60

[33] Wiemer S, Wyss M. Mapping spatial variability of the frequency-magnitude distribution of earthquakes. Advances in Geophysics. 2002;45:259-302

[34] Cao A, Gao S. Temporal variation of seismic b-values beneath northeastern Japan island arc. Geophysical Research Letters. 2002;29(9):48-41

[35] Wyss M, Stefansson R. Nucleation points of recent main shocks in southern Iceland, mapped by b-values. Bulletin of the Seismological Society of America. 2006;96(2):599

[36] Console R, Murru M, Catalli F, Falcone G. Real time forecasts through an earthquake clustering model constrained by the rate-and-state constitutive law: Comparison with a purely stochastic ETAS model. Seismological Research Letters. 2007;78(1):49

[37] Zhou P, Xia S, Sun J, Cao J, Xu H, Zhao F, Chen C. Spatial variations of b-values in the coastal area of Guangdong. Journal of Ocean University of China. 2018;17(1):177-185

[38] Leptokaropoulos K, Staszek M, Lasocki S, Mart’ınez-Garz'on P, Kwiatek G. Evolution of seismicity in relation to fluid injection in the North-Western part of The Geysers geothermal field. Geophysical Journal International. 2018;212:1157-1166

[39] Urbancic T, Trifu C, Long J, Young R. Space-time correlations of b values with stress release. Pure and Applied Geophysics. 1992;139(3):449-462

[40] Singh S, Carton H, Tapponnier P, Hananto N, Chauhan A, Hartoyo D, Bayly M, Moeljopranoto S, Bunting T, Christie P, Others. Seismic evidence for broken oceanic crust in the 2004 Sumatra earthquake epicentral region. Nature Geoscience. 2008;1(11):777-781

[41] Schorlemmer D, Wiemer S, Wyss M. Earthquake statistics at Parkfield: 1. Stationarity of b values. Journal of Geophysical Research. 109, B12308, DOI: 10.1029/2004JB003235

[42] Schorlemmer D, Wiemer S, Wyss M. Variations in earthquake-size distribution across different stress regimes. Nature. 2005;437(7058):539-542

[43] Wyss M, Sammis C, Nadeau R, Wiemer S. Fractal dimension and b-value on creeping and locked patches of the San Andreas fault near Parkfield, California. Bulletin of the Seismological Society of America. 2004;94(2):410

[44] Wyss M, Matsumura S. Verification of our previous definition of preferred earthquake nucleation areas in Kanto-Tokai, Japan. Tectonophysics. 2006;417(1-2):81-84

[45] Nuannin P, Kulhanek O, Persson L. Spatial and temporal b value anomalies preceding the devastating off coast of NW Sumatra earthquake of December 26, 2004. Geophysical Research Letters. 2005;32(11):L11307

[46] Nuannin P. The Potential of b-Value Variations as Earthquake Precursors for Small and Large Events [Ph.D. thesis]. Uppsala University; 2006

[47] Del Pezzo E, Esposito A, Giudicepietro F, Marinaro M, Martini M, Scarpetta S. Discrimination of earthquakes and underwater explosions using neural networks. Bulletin of the Seismological Society of America. 2003;93(1):215 
[48] Amorese D, Grasso J, Rydelek P. On varying b-values with depth: Results from computer-intensive tests for Southern California. Geophysical Journal International. 2010;180(1):347-360

[49] Wyss M, Lee WH. Time variations of the average earthquake magnitude in Central California. In: Proceedings of the conference on tectonic problems of the San Andreas fault system; 1973, edt. R. Kovach \& A. Nur. Stanford University Geol. Sci. pp. 24-42

[50] Main I, Meredith P, Jones C. A reinterpretation of the precursory seismic b-value anomaly from fracture mechanics. Geophysical Journal International. 1989;96(1):131-138

[51] Gupta H, Singh H. Earthquake swarms precursory to moderate to great earthquakes in the Northeast India region. Tectonophysics. 1989;167(2-4):285-298

[52] Wyss M, Booth D. The IASPEI procedure for the evaluation of earthquake precursors. Geophysical Journal International. 1997;131(3):423-424

[53] Mori J, Abercrombie R. Depth dependence of earthquake frequency-magnitude distributions in California: Implications for rupture initiation. Journal of Geophysical Research. 1997;102(15):081-015

[54] Power J, Wyss M, Latchman J. Spatial variations in the frequency-magnitude distribution of earthquakes at Soufriere Hills volcano, Montserrat, West Indies. Geophysical Research Letters. 1998;25(19):3653-3656

[55] Warren N, Latham G. An experimental study of thermally induced microfracturing and its relation to volcanic seismicity. Journal of Geophysical Research. 1970;75(23):4455-4464

[56] Amelung F, King G. Earthquake scaling laws for creeping and non-creeping faults. Geophysical Research Letters. 1997;24(5):507-510

[57] Beauval C, Scotti O. Quantifying sensitivities of PSHA for France to earthquake catalog uncertainties, truncation of ground-motion variability, and magnitude limits. Bulletin of the Seismological Society of America. 2004;94(5):1579

[58] Kulhanek O. Seminar on b-value. Prague Centre of Mathematical Geophysics, Meteorology, and their Applications (MAGMA); 2005

[59] Hauksson E, Jones L, Hutton K. The 1999 Mw 7.1 Hector mine, California, earthquake sequence: Complex conjugate strike-slip faulting. Bulletin of the Seismological Society of America. 2002;92(4):1154

[60] Guttorp P. On least-squares estimation of $b$ values. Bulletin of the Seismological Society of America. 1987;77(6):2115

[61] Aki K. Maximum likelihood estimate of $\mathrm{b}$ in the formula $\log \mathrm{N}=\mathrm{a}-\mathrm{bM}$ and its confidence limits. Bulletin of the Earthquake Research Institute Tokyo University. 1965;43:237-239

[62] Bender B. Maximum likelihood estimation of $b$ values for magnitude grouped data. Bulletin of the Seismological Society of America. 1983;73(3):831

[63] Utsu T. A method for determining the value of $b$ in a formula $\log n=a-b M$ showing the magnitude-frequency relation for earthquakes. Geophys. Bull. Hokkaido Univ. 1965;13:99-103 
[64] Shi Y, Bolt B. The standard error of the magnitude-frequency b value. Bulletin of the Seismological Society of America. 1982;72(5):1677

[65] Felzer K. Calculating the Gutenberg-Richter $b$-Value. USGS publication; 2007

[66] Melojevic S. Power-law distributions in information science-making the case for logarithmic binning. Journal of the American Society for Information Science and Technology. 2010;61(12):2417-2425 
